\title{
Clinical Presentation and Follow Up of Children With Congenital Toxoplasmosis in Brazil
}

\author{
Marco A. P. Sáfadi, Eitan N. Berezin, \\ Calil K. Farhat and Eduardo S. Carvalho
}

\begin{abstract}
Division of Pediatric Infectious Diseases, Santa Casa de São Paulo School of Medical Sciences; Division of Pediatric Infectious Diseases, Federal University of São Paulo, São Paulo, SP, Brazil
\end{abstract}

\begin{abstract}
We evaluated the clinical presentation and determined the ocular and neurologic sequelae in children with congenital toxoplasmosis in Brazil, taking into consideration the shortage of national publications on this disease. Follow-up evaluations were made of 43 children with congenital toxoplasmosis referred to Santa Casa de São Paulo, during a period of at least five years. Selection of the cases was based in clinical and laboratory criteria. A clear predominance of children with subclinical presentation of the disease at birth $(88 \%)$ was found. Of the 43 children, 22 (51\%) developed neurological manifestations. Using skull radiography, we detected neuroradiologic alterations in seven children (16\%) and with tomography in 33 children (77\%). Neurological sequelae were identified in 15 children $(54 \%)$ in the group with cerebral calcifications and in 7 $(47 \%)$ in the group without cerebral calcifications. We observed chorioretinitis in $95 \%$ of the cases. Reactivation of cicatricial lesions and the emergence of new ocular lesions were observed in five cases. The most frequent neurological manifestation was a delay in neuropsychomotor development. Most remarkable was the finding that cerebral calcifications were not associated with a higher incidence of neurological sequelae among the children. Chorioretinitis was the main ocular sequel of the infection, found in nearly all children; it can manifest years from birth, even in children submitted to specific therapy during the first year of life, highlighting the importance of a follow-up of these children.

Key Words: Congenital toxoplasmosis, chorioretinitis, neurologic manifestation.
\end{abstract}

Toxoplasmosis is one of the most common infections in humans [1,2,3]. Acute infection with $T$. gondii usually is asymptomatic in children and adults, but serious clinical disease can result from a congenital infection. The vertical transmission rate is directly proportional to the gestational age in which the mother is infected, the severity of fetal disease being inversely related to it. Infants with congenital toxoplasmosis are asymptomatic in about $70 \%$ to $90 \%$ of the cases. However, most of these children will develop sequelae

Received on 07 February 2003; revised 20 July 2003.

Address for correspondence: Dr.. Marco Aurélio Palazzi Sáfadi. Rua Lourenço de Almeida, No 132, ZIP 04508-000, São Paulo, SP, Brazil. Phone: (5511) 3885-7122, Fax: (5511) 3842-1793.

E-mail:masafadi@ sanet.com.br.

The Brazilian Journal of Infectious Diseases 2003;7(5):325-331 (C) 2003 by The Brazilian Journal of Infectious Diseases and Contexto Publishing. All rights reserved. during childhood or early adult life $[4,5,6,7]$. Studies have shown that even in infants with subclinical disease at birth and who have had appropriate therapy in the first year of life, there is risk of later appearance of ocular lesions $[8,9,10]$.

Most infants have a subclinical infection, with no overt disease at birth, impeding prompt initiation of therapy in almost all cases, though it is vital to prevent future sequelae of the disease. Consequently, unless pre-natal serological screening is institutionalized, allowing for the diagnosis of the mother's infection, we will continue missing the diagnosis of congenital toxoplasmosis in many children, who may later present sequelae (ocular and/or neurological) of the disease [8].

We describe the results of a follow-up evaluation of 43 children with congenital toxoplasmosis in a tertiary hospital in São Paulo, and analyze the main epidemiological aspects involved with the acquisition 
of the mother's infection, the clinical presentation, neuroradiological alterations and outcomes of these children, comparing our data with other studies. There arefew publications about this disease in children in Brazil.

\section{Materials and Methods}

We included in this prospective study infants and children, with a confirmed diagnosis of congenital toxoplasmosis, referred by their physicians to the Division of Infectious Diseases of the Department of Pediatrics, Santa Casa de São Paulo, Brazil, from March 1990 until January 1999.

Infants and children were referred to us by general pediatricians, neonatologists, ophthalmologists and neurologists of our tertiary hospital, after suspicion of possible congenital toxoplasmosis by clinical, neurological and ophthalmological examinations, or by laboratory tests.

Congenital toxoplasmosis was defined by the following criteria:

1.Newborn and infants under six months of age: positive serology, with Toxoplasma-specific IgM (DS IgM ELISA), or a significant increase in the IgG titres (ELISA) in serial samples, analyzed simultaneously [11].

2.Children of any age: chorioretinitis with active or atrophic scar lesions, characteristic of toxoplasmosis, and positive serology (ELISA) for toxoplasmosis. Besides the characteristic ocular lesions, at least one of the following criteria, known to be indicators of congenital infection [1]: cranial CT alterations compatible with congenital infection (diffuse intraparenchymatous cerebral calcifications), strabismus and nystagmus since the early months of life.Positive serology for syphilis, HIV, IgM anti-bodies for Cytomegalovirus, and suspected tuberculosis or candidiasis, were considered excluding criteria in this study [12].

All children were evaluated at least once by the authors, and observed for a minimum period of 5 years. A detailed history was taken; risk factors for acquisition of toxoplasmosis during the pregnancy were assessed. For neurological and psychomotor development evaluation we used the DENVER scale [13]. Besides a delay in neuropsychomotor development, we considered hydrocephalus, microcephalus, seizures and motor sequelae to be neurological sequelae. Eye examinations were performed by ophthalmologists from the subnormal vision group, and included visual acuity with correction, external exam and direct and indirect ophthalmoscopy, with mapping of the retina, repeated every six months during the follow-up. Radiological evaluation consisted of cranial X-rays and computed tomography (CT) of the brain (before and after the administration of intravenous iodine contrast, from the orbit-meatal plan in the direction of the vertex) and were carried out in all children.

The treatment regimen ininfants consisted of four weeks of sulfadiazine $(100 \mathrm{mg} / \mathrm{kg} / \mathrm{d})$ in two divided doses, plus pyrimethamine $(1 \mathrm{mg} / \mathrm{Kg} / \mathrm{d})$ and folinic acid (5 mg once a week), alternated with four weeks of spiramycin (100 $\mathrm{mg} / \mathrm{kg} / \mathrm{d}$ ) in two divided doses to complete a one-year course. Children referred to us who were older than one year were not submitted to treatment, unless they manifested active chorioretinitis, in which case a regimen of sulfadiazine $(100 \mathrm{mg} / \mathrm{kg} / \mathrm{d})$ in two divided doses, plus pyrimethamine $(1 \mathrm{mg} / \mathrm{kg} / \mathrm{d})$, folinic acid $(5 \mathrm{mg}$ once a week) and prednisone, $1 \mathrm{mg} / \mathrm{kg} / \mathrm{d}$ were given until two weeks after the signs and symptoms had normalized.

\section{Statistical analysis}

Chi-square $\left(\mathrm{X}^{2}\right)$ tests for $\mathrm{K}$ independent samples were used to determine the significance of the differences in the incidence of neurological manifestations between the groups of children with congenital toxoplasmosis diagnosed until six months of age compared to those diagnosed after seven months of age. The Chi-square $\left(\mathrm{X}^{2}\right)$ test was also used to determine if there were significant differences in the incidence of neurologic manifestations between the groups of children with and without cerebral calcifications. The alpha level for significance was 0.05 [14].

We used a proportion test to determine whether radiological evaluation through X-ray and tomography were equivalent. At a 5\% significance level, for this test, the critical value for the test statistic $\mathrm{Z}=1.64$ [14]. 


\section{Results}

Of a total of 74 children, initially selected, 43 were included in the study, with a diagnosis of congenital toxoplasmosis, according to the criteria that we adopted. There were no deaths among the cases under surveillance.

Twenty- three children (54\%) were male and 20 (46\%) were female. The predominant age group, at diagnosis, was children older than 25 months (Table 1). Most of the children (84\%) weighed $\geq 2,500$ grams at birth, with only 7 children $(16 \%)<2,500$ grams at birth.

Table 2 summarizes the main predisposing risk factors found in the families of the children studied. The presence of cats in the house was the main risk factor (44\%), followed by the habit of eating raw meat (14\%). Forty two percent of the women did not report any of the risk factors.

Of the 43 children, $22(51 \%)$ had at least one neurological sequelae (Table 3 ). There was a significantly higher incidence of neurological sequelae in the group of children whose diagnosis was made by six months of age, compared to the group for which the diagnosis was made after 7 months of age $\left(\mathrm{X}^{2}=9.96\right)$.

We found chorioretinitis characteristic of toxoplasmosis in 41 children (95\%). In 36 cases it was in both eyes and it occurred in just one eye in five cases. Three children, with normal initial eye examinations, developed chorioretinitis years later, despite being treated during the first year of life. Five children had recurrences of active chorioretinitis during the followup. The other ocular findings are in Table 4.

With X-rays, we observed cerebral calcifications in only seven children (16\%). However, using the CT, we found alterations in $33(77 \%)$, characterized predominantly by diffuse intraparenchymatous calcifications in 28 children and cortical atrophy with ventricular dilatation in 13 children. In 10 children the CT was normal at first, and it remained so in further exams. Thus, we found CT to be significantly more sensitive than the X-ray exam, for the detection of radiological alterations in the central nervous system of children with congenital toxoplasmosis $(\mathrm{Pt} .=0.7674)$.
When we analyzed the incidence of neurologic sequelae in children with cerebral calcifications, compared with children who did not present cerebral calcifications (Table 5), we found no evidence that cerebral calcifications in children with congenital toxoplasmosis is associated with a higher incidence of neurological sequelae $\left(\mathrm{X}^{2}=0.40, \mathrm{P}>0.5\right)$.

\section{Discussion}

In Brazil investigations carried have always found higher prevalences of Toxoplasma infection [15,16,17] than those observed in North American populations $[18,19]$, while they are comparable to that found in other countries, such as France [1,20,21]. Prospective studies have shown that approximately $30 \%$ of newborns from mothers who had toxoplasmosis during pregnancy acquire the infection [20]. Most congenitally-infected children are free of symptoms at birth, not allowing for an early diagnosis. However, among infected newborns, with subclinical disease, up to $85 \%$ develop chorioretinitis during childhood and adolescence, and about $40 \%$ have neurological sequelae [4]. These data alerted the medical community to develop serological screening programs, for the early detection and treatment of cases that lacked a prenatal diagnosis.

We followed, during at least five years, 43 children with congenital toxoplasmosis. Because of the impossibility of making this study with a randomized control group, there are a few limitations that must be considered in interpreting the data. We highlight, however, the number of cases included in our study. Koppe et al. [6] followed, prospectively, 11 children; Wilson et al. [4] evaluated, prospectively, 24 children; Koskeniemi, Lappalainen and Hedman [22] studied, retrospectively, 32 children with symptomatic congenital toxoplasmosis; Mcauley et al. [10] followed, during 10 years, 44 children with symptomatic congenital toxoplasmosis. All of these studies used methodology similar to what we used in our study. In our region, we highlight the study made by Diniz [23], who followed the clinical and serological evolution of 19 infants with congenital toxoplasmosis. 
Table 1. Distribution of cases by age-group, at the diagnosis of congenital toxoplasmosis

\begin{tabular}{cc}
\hline Age (months) & Number of children (\%) \\
\hline $0-1$ & $5(12)$ \\
$2-6$ & $11(26)$ \\
$7-24$ & $10(23)$ \\
$\geq 25$ & $17(40)$ \\
Total & $\mathbf{4 3 ( 1 0 0 )}$ \\
\hline
\end{tabular}

Table 2. Presence of predisposing risk factors for acquisition of maternal toxoplasmosis

\begin{tabular}{lc}
\hline Risk factor & Number of cases ( \%) \\
\hline Presence of cats & $19(44.19)$ \\
Ingestion of under-cooked meat & $6(14)$ \\
Contact with sand and soil & $4(9.3)$ \\
None indicated & $18(42)$ \\
Total & $\mathbf{4 3}(\mathbf{1 0 0})$ \\
\hline
\end{tabular}

Table 3. Comparison of the incidence of neurological sequelae in the group of children whose diagnosis of congenital toxoplasmosis was made during the first six months of age (group I), compared to the group where the diagnosis was made after seven months of age (group II)

\begin{tabular}{lccc}
\hline Clinical findings & $\begin{array}{c}\text { Group I } \\
(\mathbf{n}=\mathbf{1 6})\end{array}$ & $\begin{array}{c}\text { Group II } \\
(\mathbf{n = 2 7 )}\end{array}$ & $\begin{array}{c}\text { Total } \\
(\mathbf{n = 4 3 )}\end{array}$ \\
\hline Neurological sequelae & $13(81 \%)$ & $9(33 \%)$ & $22(51 \%)$ \\
Normal & $3(19 \%)$ & $18(67 \%)$ & $21(49 \%)$ \\
\hline
\end{tabular}

$\mathrm{X}^{2}=9.96, \mathrm{P}<0.05$.

Table 4. Ophthalmological findings for children with congenital toxoplasmosis

\begin{tabular}{lcr}
\hline $\begin{array}{l}\text { Ophthalmological } \\
\text { findings }\end{array}$ & $\begin{array}{c}\text { Number of children } \\
(\mathbf{n = 4 3 )}\end{array}$ & $\mathbf{( \% )}$ \\
\hline Chorioretinitis & 41 & 95.0 \\
Strabismus & 21 & 49.0 \\
Nystagmus & 20 & 47.0 \\
Microphthalmia & 4 & 9.3 \\
Cataract & 1 & 2.3 \\
No. sequelae & 2 & 4.7 \\
\hline
\end{tabular}


Table 5. Correlation between neurological and developmental outcomes and intracranial calcifications in the tomography of children with congenital toxoplasmosis

\begin{tabular}{lcccc}
\hline Clinical findings & \multicolumn{2}{c}{ Presence of intracranial calcifications } & \multicolumn{2}{c}{ No intracranial calcifications } \\
& $\mathbf{N = \mathbf { 2 8 }}$ & $\mathbf{( \% )}$ & $\mathbf{N = \mathbf { 1 5 }}$ & $(\boldsymbol{\%})$ \\
\hline Neurologic sequelae & 15 & 54 & 7 & 47 \\
Normal & 13 & 46 & 8 & 53 \\
Total & $\mathbf{2 8}$ & $\mathbf{1 0 0}$ & $\mathbf{1 5}$ & $\mathbf{1 0 0}$ \\
\hline
\end{tabular}

$\mathrm{X}^{2}=0.40, \mathrm{P}>0.5$

In the analysis of the age at which the diagnosis of congenital toxoplasmosis was made, only five cases (12\%) manifested disease during the neonatal period. Prospective studies [4,24,25] of congenital toxoplasmosis have always found a predominance of subclinical forms of the disease, in approximately $80 \%$ to $90 \%$ of the cases. The clinical forms of presentation of congenital toxoplasmosis, in our study, are similar to those observed in other studies. It is possible that a more detailed evaluation in the neonatal period could have detected clinical manifestations of the disease in some of these children. Nevertheless, the routine evaluations made in our neonatal centers were not sufficient to establish a diagnosis in most of the infants in our study.

We evaluated the birth weight of the children included in our study; in seven cases (16\%) birth weight was under 2500 grams. In none of these cases was the diagnosis made during the neonatal period. Apart from Alford, Stagno and Reynolds [24], who observed low weight at birth and prematurity in $50 \%$ of the children with subclinical congenital toxoplasmosis, the remaining reports of children with congenital toxoplasmosis report a low incidence of low weight at birth $[5,10,26]$. We also found a low incidence of low weight at birth.

This observation is important since most of our neonatal services examine infants for congenital toxoplasmosis only after a report of retarded intrauterine growth, or low weight at birth, emphasizing the importance of pre-natal screening tests. Because it is not feasible to screen all pregnant women, a newborn screening program consisting of serological testing of all newborns through testing of dried blood specimens for IgM antibodies against $T$. gondii would be an efficient alternative in our setting to detect subclinically infected infants born to untreated mothers, reducing long term neurological and ophthalmological sequelae through the early initiation of treatment.

The main predisposing risk factors for the acquisition of toxoplasmosis during pregnancy was the presence of cats in the house, followed by the habit of eating raw or undercooked meat and the practice of gardening. In a high percentage of the children $(41 \%)$ we could not detect risk factors. In our setting, Diniz [23] has reported risk factors during pregnancy in $37 \%$ of the mothers of children with congenital toxoplasmosis (contact with cats also being the main factor). In the United States Mcauley et al. [10] found risk factors during pregnancy in $86 \%$ of the mothers (contact with material potentially contaminated with cat feces being the main risk factor, found in $48 \%$ of the mothers). Studies made in France indicate the ingestion of raw or undercooked meat as the main risk factor in that population. Thus, our epidemiological data indicate a predominance of transmission of this disease in pregnant women through contact with cat feces, as well as a high incidence of cases in which it was not possible to detect the risk factors involved, possibly reflecting cultural habits of our population.

Dividing the children in our study into two groups, the first composed of children whose diagnosis was made before the six months of age and the second, of children whose diagnosis was made after seven months of age, we observed a significantly greater frequency of neurological sequelae in the first group $(81 \%)$ than in the second group (33\%). These results confirm previous 
observations [1] that the later the diagnosis the lower the incidence of neurological sequelae, with most of the children presenting ocular forms of the disease. The earlier age at diagnosis probably led to the inclusion of more severely involved children in the first group of our study, which could help explain our findings.

We observed a high incidence of chorioretinitis (95\%) among these children. Similar results have been reported by several authors $[1,4]$. Koppe et al. [6] initially found chorioretinitis in $37 \%$ of the children they evaluated, and after a 20 year follow up they observed that $83 \%$ of the children developed chorioretinitis. Lower incidences were reported by Guerina et al. [25], who found them in $25 \%$ of the cases studied, and by Couvreur et al. [5], who found them in $22 \%$ of the cases. The possible justification for the lower incidence of ocular lesions in these latter two studies is due to the fact that neither of them made a long term follow up of the patients, as we know that ocular lesions can occur at a later time, due to the permanence of inactive Toxoplasma cysts in the retina, which can be activated at any given moment. The high incidence of chorioretinitis in our study was probably due to the fact that many of the children were older than two years at the moment of diagnosis, made after finding visual disorders, and due to the long follow up period (at least five years), which allowed the diagnosis of ocular lesions that did not exist at initial evaluation.

Three children, who initially had normal eye examination results, developed chorioretinitis years after the diagnosis, during the follow-up, despite having been treated during the first year of life. Five other children, with late diagnosis of congenital toxoplasmosis and consequently not treated during the first year of life, manifested reactivation of previously healed ocular lesions. These patients went through two to three month therapeutic cycles, with follow up exams by ophthalmologists, until it was clear that the lesions were healed. Late ocular lesions in children who have congenital toxoplasmosis is widely documented in the literature, including children adequately treated during the first year of life $[9,27,28]$, confirming the necessity of an intensive follow up for these children.
We compared the results obtained with the simple cranial X-ray and the CT, which led us to the conclusion that tomography is a significantly more sensitive exam than X-rays for the detection of cerebral calcifications. Mcauley et al. [10] compared cranial CT with magnetic resonance imaging (MRI) and ultra-sound in infants with congenital toxoplasmosis, concluding that tomography was the most sensitive exam for the detection of neuroradiological alterations (especially calcifications and cortical atrophy with ventricular dilatation) in congenital toxoplasmosis.

We examined diffuse intraparenchymatous cerebral calcifications found in the tomography as an indicator of neurological outcome; there was no significant correlation. This remarkable finding in our study confirms the findings of some authors like Mussbichler [29], who, after extensive evaluation of X-rays with cerebral calcifications in children with congenital toxoplasmosis, stated that the presence of calcifications in the meninges and areas of the caudate nucleus indicate a poor prognosis and conversely, disseminated nodular calcifications do not necessarily suggest a poor prognosis. Patel et al. [30] demonstrated that after being treated, the children had a reduction in or remission of cerebral calcifications associated with an improvement in their neurological condition. In our study, there was a predominance of sparse, scattered nodular calcifications in the tomographic images, diffuse in the cerebral parenchyma, many of them discovered fortuitously, allowing us to conclude that this pattern of calcifications is not an indicator of neurological outcome.

The analysis of our data has allowed us to conclude that the vast majority of the children had subclinical forms of presentation of the disease at birth, without a higher incidence of prematurity or low weight at birth. The main neurologic sequelae observed among the children was a delay in their neuropsychomotor development, with significantly more frequent neurological sequelae in the group of children whose diagnosis was made before six months of age than in the group of children whose diagnosis was made after seven months. The presence of cerebral calcifications was not associated with a higher incidence of neurologic sequelae among these children. Chorioretinitis was the main 
sequelae of the infection, found in $95 \%$ of the cases; it can manifest years after birth, even in children submitted to specific therapy during the first year of life.

\section{References}

1. Couvreur J., Desmonts G.. Congenital and maternal toxoplasmosis: A review of 300 congenital cases. Dev Med Child Neurol 1962;4:519-30.

2. Feldman H.A., Miller L.T. Serological study of toxoplasmosis prevalence. Am J Hyg 1956;64:320-35.

3. Harboe A. Toxoplasma dye titers in 1,600 blood donors in Oslo. Acta Pathol Microbiol Scand 1952;93:325-31.

4. Wilson C.B., Remington J.S., Stagno S., Reynolds D.W. Development of adverse sequelae in children born with subclinical congenital Toxoplasma infection. Pediatrics 1980; 66 :767-74.

5. Couvreur J., Desmonts G., Tournier G., Szusterkac M. Etude d'une série homogéne de 210 cas de toxoplasmose congénitale chez des mourrissons âges de 0 à 11 mois et dépistés de façon prospective. Ann Pédiatr 1984;31:815-9.

6. Koppe J.G., Sieger L.D.H., Bonnet R.H. Results of 20year follow-up of congenital toxoplasmosis. Lancet 1986;1:254-6.

7. O'Neill J.F. The ocular manifestations of congenital infection: A study of the early effect and long-term outcome of maternally transmitted rubella and toxoplasmosis. Trans Am Ophthalmol Soc 1998;96:813-79.

8. Gras L., Gilbert R.E., Ades A.E., Dunn D.T. Effect of prenatal treatment on the risk of intracranial and ocular lesions in children with congenital toxoplasmosis. Int $\mathbf{J}$ Epidemiol 2001;30(6):1309-13.

9. De Vroede M., Dodion J., De Meuter F., et al. Congenital toxoplasmosis: Late appearance of retinal lesions after treatment. Acta Paediatr Scand 1979;68: 761-2.

10. McAuley J., Boyer K.M., Patel D., et al. Early and longitudinal evaluations of treated infants and children and untreated historical patients with congenital toxoplasmosis: The Chicago collaborative treatment trial. Clin Infect Dis 1994;18:38-72.

11. Wilson C.B., Remington J.S. Toxoplasmosis. In: Feigin, R.D. \& Cherry, J.D. Textbook of Pediatric Infectious Diseases. 3.ed. Philadelphia: WB Saunders; 1992:2057-70.

12. Perkins E.S. Ocular Toxoplasmosis. Br J Ophtalmol 1973;57:1-17

13. Frankenburg W.K., Goldstein A.D., Camp B.W. The revised Denver Developmental Screening Test: Its accuracy as a screening instrument. The Journal of Pediatrics 1971;79:988-95.

14. Morettin P.A., Bussab W.O. Estatística Básica. 2.ed. São Paulo, Atual, 1984.
15. Guimarães A.C.S., Kawarabavashi M., Borges M.M., et al. Regional variation in toxoplasmosis seronegativity in the São Paulo metropolitan area. Rev Inst Med Trop S Paulo 1993;35:479-83.

16. Tonelli E., Araújo F.G., Oréfice F., Brandão L.L. Diagnóstico da toxoplasmose - infecção em acadêmicos de Medicina pela reação de imunofluorescência indireta. Rev Ass Med Minas Gerais 1971;22:63-6.

17. Castilho E.A. An estimation of the incidence of congenital toxoplasmosis in São Paulo City, Brasil. Rev Inst Med Trop São Paulo 1976;18:202-5.

18. Smith K.L., Wilson M., Hightower A.W. Prevalence of Toxoplasma gondii antibodies in US military recruits in 1989: Comparison with data published in 1965. Clin Infect Dis 1996;23:1182-3.

19. Montoya J., Remington J. Toxoplasma gondii. In: MandellPrinciples and Practice of Infectious Diseases, $5^{\text {th }}$ ed. Churchill Livingstone, 2000:2858-81.

20. Desmonts G., Couvreur J. Congenital toxoplasmosis: A prospective study of 378 pregnancies. N Engl J Med 1974;290:1110-6.

21. Remington J.S., McLeod R., Desmonts G. Toxoplasmosis. In: Remington J.S., Klein J.O. Infectious Diseases of the Fetus and Newborn Infant. 5th ed. Philadelphia: W.B. Saunders Co.; 2001:205-346.

22. Koskiniemi M., Lappalainen M., Hedman K. Toxoplasmosis needs evaluation: An overview and proposals. Am J Dis Child 1989;143:724-8.

23. Diniz E.M.A. Análise da evolução clínica e sorológica de recém-nascidos portadores de toxoplasmose congênita. São Paulo [Tese - Doutorado - Faculdade de Medicina da Universidade de São Paulo]; 1984.

24. Alford J.R. C.A., Stagno S., Reynolds D.W. Congenital toxoplasmosis: Clinical, laboratory, and therapeutic considerations, with special reference to subclinical disease. Bull N Y Acad Med 1974;50:160-81.

25. Guerina N.G. Congenital infection with Toxoplasma gondii. Pediatr Ann 1994;23:138-51.

26. Hohlfeld P., Daffos F., Thulliez P., et al. Fetal toxoplasmosis: Outcome of pregnancy and infant follow-up after in utero treatment. J Pediatr (St. Louis) 1989; 115:765-9.

27. Koppe J.G., Meenken C. Congenital toxoplasmosis, later relapses and treatment. Acta Paediatr 1999;88:586-8.

28. Meenken C., Assies J., Nieuwenhuizen A., et al. Long term ocular and neurological involvement in severe congenital toxoplasmosis. British journal of Ophthalmology 1995;79:581-4.

29. Müssbichler H. Radiologic study of intracranial calcifications in congenital toxoplasmosis. Acta Radiol 1968; 7:369-79.

30. Patel D.V., Holfels E.M., Vogel N.P., et al.. Resolution of intracranial calcifications in infants with treated congenital toxoplasmosis. Radiology 1996;199:433-40. 